Check for updates

Cite this: Chem. Commun., 2020, 56,8802

Received 4th June 2020,

Accepted 24th June 2020

DOI: $10.1039 / \mathrm{dOcc03934a}$

rsc.li/chemcomm

\section{Fragment-oriented synthesis: $\beta$-elaboration of cyclic amine fragments using enecarbamates as platform intermediates $\dagger$}

\author{
Alexandre F. Trindade, ${ }^{a}$ Emily L. Faulkner, (D) ${ }^{a}$ Andrew G. Leach, (DD ${ }^{b}$ \\ Adam Nelson (D) $* a c$ and Stephen P. Marsden (D) *a
}

A strategy for the $\beta-\mathrm{sp}^{3}$ functionalisation of cyclic amines is described. Regioselective conversion of protected amines to enecarbamates is achieved through electrochemical oxidation; these intermediates can be derivatised by functionalised alkyl halides under photoredox catalysis. The potential of the methods is highlighted by direct growth of a DCP2B-binding fragment.

Fragment-based ligand discovery is well established as a powerful approach for the discovery of new drugs, with four molecules developed in this way in clinical usage and many more in advanced trials. ${ }^{1}$ Fragments are typically smaller molecules than those used in high-throughput screening, meaning they explore chemical space more efficiently and, while the absolute potency of hit molecules is generally low, they bind their targets with high ligand efficiency (binding energy per non-hydrogen atom). A key step in the process is to 'grow' fragment hits from potentially any position without disrupting existing favourable binding interactions, in order to improve potency whilst preserving high ligand efficiency. ${ }^{2}$

Medicinal chemistry is dominated by a limited reaction toolkit that is heavily focused on heteroatom functionalisation. ${ }^{3}$ Given the strict molecular weight constraints applied to fragments, there are usually limited opportunities to grow them by elaborating functional groups that are not engaged in binding interactions. ${ }^{4}$ Fragment growth thus frequently requires time- and resourceintensive de novo synthesis, and can become a bottleneck in discovery. ${ }^{5}$ This is illustrated in the discovery of $\mathbf{1}$ (Fig. 1, panel A), a sub-micromolar lead compound against X-linked Inhibitor of Apoptosis Protein. ${ }^{6}$ Analysis of the binding pose of the low

${ }^{a}$ School of Chemistry, University of Leeds, Leeds LS2 9JT, UK.

E-mail:s.p.marsden@leeds.ac.uk,a.s.nelson@leeds.ac.uk

${ }^{b}$ Department of Pharmacy, University of Manchester, Oxford Road,

Manchester M13 9PL, UK

${ }^{c}$ Astbury Centre for Structural Molecular Biology, University of Leeds, Leeds LS2 9JT, UK

$\dagger$ Electronic supplementary information (ESI) available: Full experimental procedures and spectral characterisation. See DOI: 10.1039/d0cc03934a potency fragment hit 2 by protein crystallography identified elaboration of the 2- and 5-positions of the piperazine ring as key opportunities. The preparation of the lead compound $\mathbf{1}$ necessitated multi-step de novo synthesis of the disubstituted piperidine core.

A more attractive alternative would be to directly elaborate the hit fragment or a closely-related 'stock' precursor. In this context, $\mathrm{C}-\mathrm{H}$ functionalisation chemistry presents an attractive opportunity to decorate otherwise inert atoms, and the many methods developed for direct functionalisation of $\mathrm{sp}^{2} \mathrm{C}-\mathrm{H}$ bonds ${ }^{7}$ complements the wide availability of $\mathrm{sp}^{2}$-rich fragments. Given their ubiquity in drug molecules and other bioactives, ${ }^{8}$ saturated cyclic amines are attractive sub-structures within $\mathrm{sp}^{3}$ rich fragments. Many methods have been developed for direct functionalization of saturated cyclic amines $\alpha$-to nitrogen ${ }^{9}$ and indeed a recent report describes $\alpha$-amino radical generation/Minisci heteroarylation as a means of selective $\alpha$-functionalisation of protected cyclic amines in the context of fragment growth. ${ }^{10}$ By contrast, however, methods for the $\beta$ - and $\gamma$-functionalisation of cyclic amines are much less common, ${ }^{11}$ meaning fragment growth along these vectors would likely fall back upon scaffold re-synthesis.

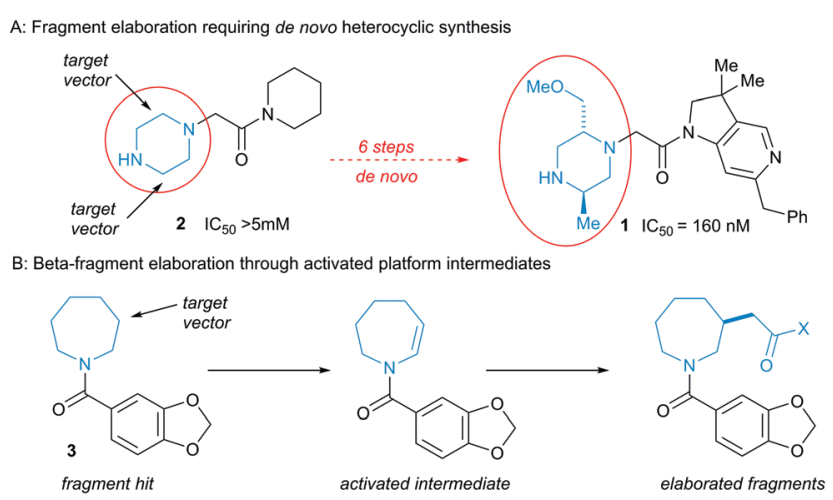

Fig. 1 De novo synthesis versus direct fragment elaboration. 
We envisaged that oxidation of protected cyclic amines to enamides or enecarbamates would afford a platform for the elaboration of fragment hits such as 3 at the $\beta$-position with a variety of functional groups, circumventing the need for de novo synthesis (Fig. 1, panel B). The utility of this process would rest both upon the efficient generation of the unsaturated amine derivatives, and the ability to introduce medicinally-relevant functionality to the $\beta$-carbon. We describe here the successful development of this approach.

Carbamate-protected amines would be useful precursors to fragments in which the nitrogen is either undecorated or, through $N$-functionalisation, a point of diversity, and so we sought methods to convert such species into enecarbamates. Employing the anodic oxidation first described by Shono, ${ }^{12}$ $\mathrm{N}$-Cbz piperidine $4 \mathbf{a}$ gave excellent conversion into methyl aminoacetal 5a (isolable in $90 \%$ yield). Attempted elimination failed using Brønsted acid ${ }^{12 b, 13}$ but the combination of TMSOTf and Hunig's base gave clean conversion to enecarbamate 6a (unoptimised $65 \%$ yield). ${ }^{14}$ Gratifyingly, the steps could be telescoped, giving $\mathbf{6 a}$ in $90 \%$ yield after purification. The protocol was extended to other carbamates (Scheme 1).

The method proved robust across a broad range of substrates, encompassing various ring sizes (e.g. 6a-c), the presence of $\beta$-heteroatoms $(\mathbf{6 g}, \mathbf{h})$ and a range of appended substituents including arenes $(\mathbf{6 e}, \mathbf{m})$, esters $(\mathbf{6 i}, \mathbf{j}, \mathbf{n})$, secondary carbamates $(\mathbf{6 o})$ and heteroarenes $(\mathbf{6 p})$. The oxidation of unsymmetrical substrates introduces the challenge of regiocontrol. With 2-substituted carbamates, literature precedent supports the predominant formation of the less-substituted 2,n-aminoacetals (although the origin of this selectivity remains unclear) ${ }^{15}$ and we did indeed observe formation of the less-substituted enecarbamates $\mathbf{6 j}$ and $\mathbf{6 k}$.

The prospects for regiocontrol from more distal substituents seemed less encouraging, but we were delighted to find reactions of 3-substituted piperidines were often also highly selective. Of the five substrates investigated, four gave single regioisomers of the isolated enecarbamates $\mathbf{6 m}-\mathbf{p}$; the reaction of $\mathrm{N}-\mathrm{Cbz}-3-$ methylpiperidine was less selective, with the less-substituted regioisomer 61 dominating in an inseparable 2:1 mixture. The origin of this regioselectivity was probed through DFT calculations (M06-2X/6-31+G** level of theory; see ESI $\dagger$ ). The proposed mechanism involves formation of an (alkoxycarbonyl)amino radical

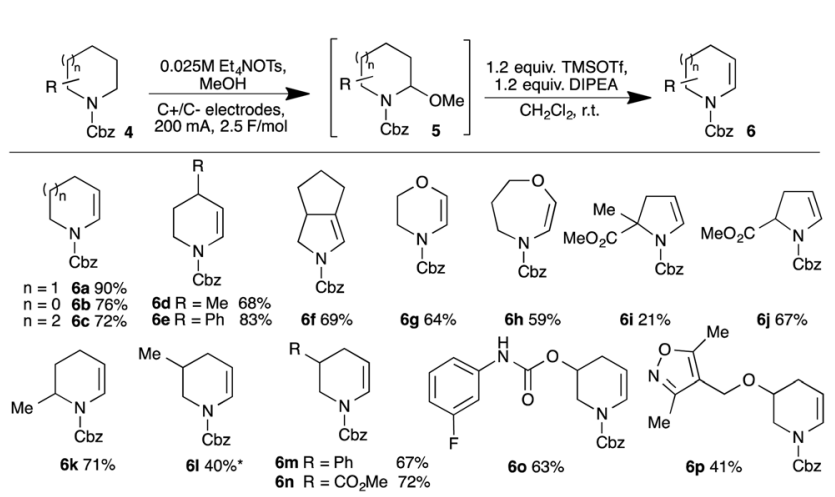

Scheme 1 Formation of enecarbamates by electrochemical oxidation/ elimination. * $2: 1$ mixture of alkene regioisomers.

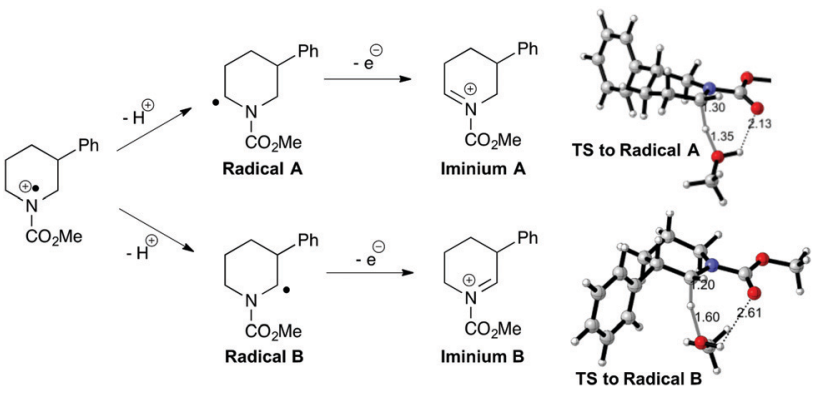

Fig. 2 Regioselectivity in electrochemical carbamate oxidation.

cation, which undergoes proton loss to generate $\alpha$-amino radicals; subsequent one-electron oxidation gives the corresponding iminium ions (Fig. 2). Radical A, leading to the observed favoured iminium ion, is higher in energy than radical $\mathrm{B}$ in both the gas and solution phase. Conversely, the observed iminium ion $\mathrm{A}$ is lower in energy than iminium B in the solution phase (moderate preference for B in the gas phase), but invoking iminium stability as the origin of the selectivity requires equilibration of the two isomers. We favour instead a kinetic explanation: modelling the transition states for solvent-mediated deprotonation of the (alkoxycarbonyl)amino radical cation revealed path A was favoured in both the gas (98:2) and solution (92:8) phase. The corresponding calculations with the 3-methyl variant showed a modest preference for path B (observed ratio within the intrinsic error of the calculations), supporting the lower observed selectivity. The origin of the selectivity is therefore likely steric.

We now turned our attention to methods for elaboration of the enecarbamates to facilitate fragment growth along the valuable vector from the $\beta$-carbon atom. Specifically, we targeted introduction of functionalised alkyl groups capable of making additional beneficial interactions with a target protein by coupling of $\alpha$-functionalised alkyl radicals with the enecarbamates as acceptor alkenes. While the coupling of enamides and enecarbamates has been reported with bromomalonates and bromoketoesters, ${ }^{16}$ reactions of the more useful monoactivated electrophiles (e.g. bromoacetates) have only been reported with highly nucleophilic enamines ${ }^{17,18}$ and their coupling with secondary enamides or enecarbamates has not been demonstrated to date. ${ }^{19}$ We therefore investigated the coupling of ethyl bromoacetate with enecarbamate $\mathbf{6 a}$ and pleasingly, following limited optimisation (ESI $\dagger$ ), we identified $\operatorname{Ir}(\mathrm{ppy})_{3}$ as an effective photocatalyst for the reaction. In methanol as solvent, the initial product of the reaction was aminoacetal 7a; subsequent treatment of this crude material with triethylsilane in the presence of $\mathrm{BF}_{3}$ etherate gave substituted Cbz-piperidine $\mathbf{8 a}$ in $92 \%$ isolated yield (Scheme 2). In addition, the reaction also worked with $N$-acetyl and $N$-benzoyl enamides (ESI $\dagger$ ), demonstrating the feasibility of direct elaboration of amide-containing fragments.

We next investigated substrate scope and found that enecarbamates derived from piperidines, azepanes, morpholines, oxazepanes and diazepanes are all suitable partners in the reaction (e.g. 8a-8e). However, Cbz-dihydropyrrole did not return the desired product, which we attributed to oxidative decomposition via Cbz-pyrrole. Consistent with this, blocking oxidation through 


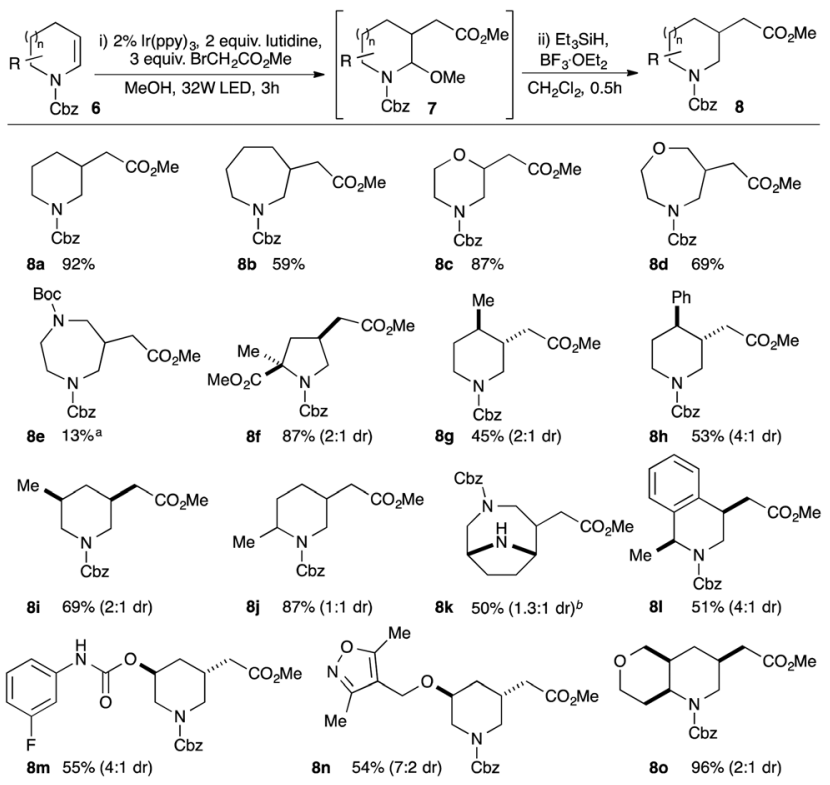

Scheme 2 Substrate scope of enecarbamates in photoredox-mediated $\beta$-carboxyalkylation; ${ }^{a}$ yield after $N$-Boc reprotection; ${ }^{b} \mathrm{~N}$-Boc protection removed in reductive step.

$\alpha, \alpha$-disubstitution allowed generation of substituted pyrrolidine 8f. Substitution on the aliphatic backbone of the enecarbamates was tolerated, allowing access to 2,5-, 3,5- and 3,4-disubstituted piperidine products such as $\mathbf{8 g}-\mathbf{j}$ : even more notably, potentially sensitive and medicinally relevant heteroatom-containing substrates also performed well (e.g. 8m,n). Addition to more complex bicyclic substrates was also successful, exemplified in the construction of both bridged (8k) and fused (8o) products. Pleasingly, alternative monoactivated alkyl electrophiles could also be utilised, allowing for introduction of side-chains bearing ketone, nitrile and sulfonyl substituents (see ESI $\dagger$ ). Details of mechanistic studies can be found in the ESI. $\dagger$

Amides are present in $c a .25 \%$ of drug candidates and amide bond formation is amongst the most widely used reactions in drug discovery ${ }^{3 b}$ and development. ${ }^{20}$ The direct introduction of amidoalkyl groups to fragments would therefore be valuable but, despite extensive efforts, we were unable to achieve efficient coupling of cyclic enecarbamates with $\alpha$-bromoacetamides (maximum 20\% yield), possibly reflecting a more difficult reduction to give $\alpha$-acetamidyl radicals. ${ }^{21}$ We therefore considered an alternative approach wherein coupling of a suitably activated ester electrophile would give an intermediate that could undergo substitution with an amine to deliver the amide in a telescoped process. As a further benefit, this approach would enable the synthesis of arrays of elaborated fragments from a single common activated ester intermediate. Pleasingly, reaction of $N$-hydroxysuccinimidyl bromoacetate 9 with enecarbamate 6a using 2 mol\% $\operatorname{Ir}(\mathrm{ppy})_{3}$ in acetonitrile gave clean conversion into the substituted enecarbamate 10a in 77\% NMR yield (Scheme 3). Simple addition of two equivalents of an amine and stirring led to the formation of the amidomethylsubstituted enecarbamates $\mathbf{1 1}$ in good yield over the two-step, onepot sequence. The reactions worked well with a broad range of primary and secondary aliphatic amines (panels a and b), including hindered $\alpha$-branched variants (e.g. 11a,j, $, \mathbf{k}, \mathbf{o})$. Medicinally-relevant substituents such as oxetanes (11k), morpholines (11n), (protected) piperazines (11m) and azine heterocycles (11c) were also tolerated, although reactions of (hetero)aromatic amines were unsuccessful even under forcing conditions. We also demonstrated that the crude enecarbamates could be directly reduced by exposure to $\mathrm{Et}_{3} \mathrm{SiH}$ and TFA, giving the saturated derivatives 12a-f in good yield (panel c).

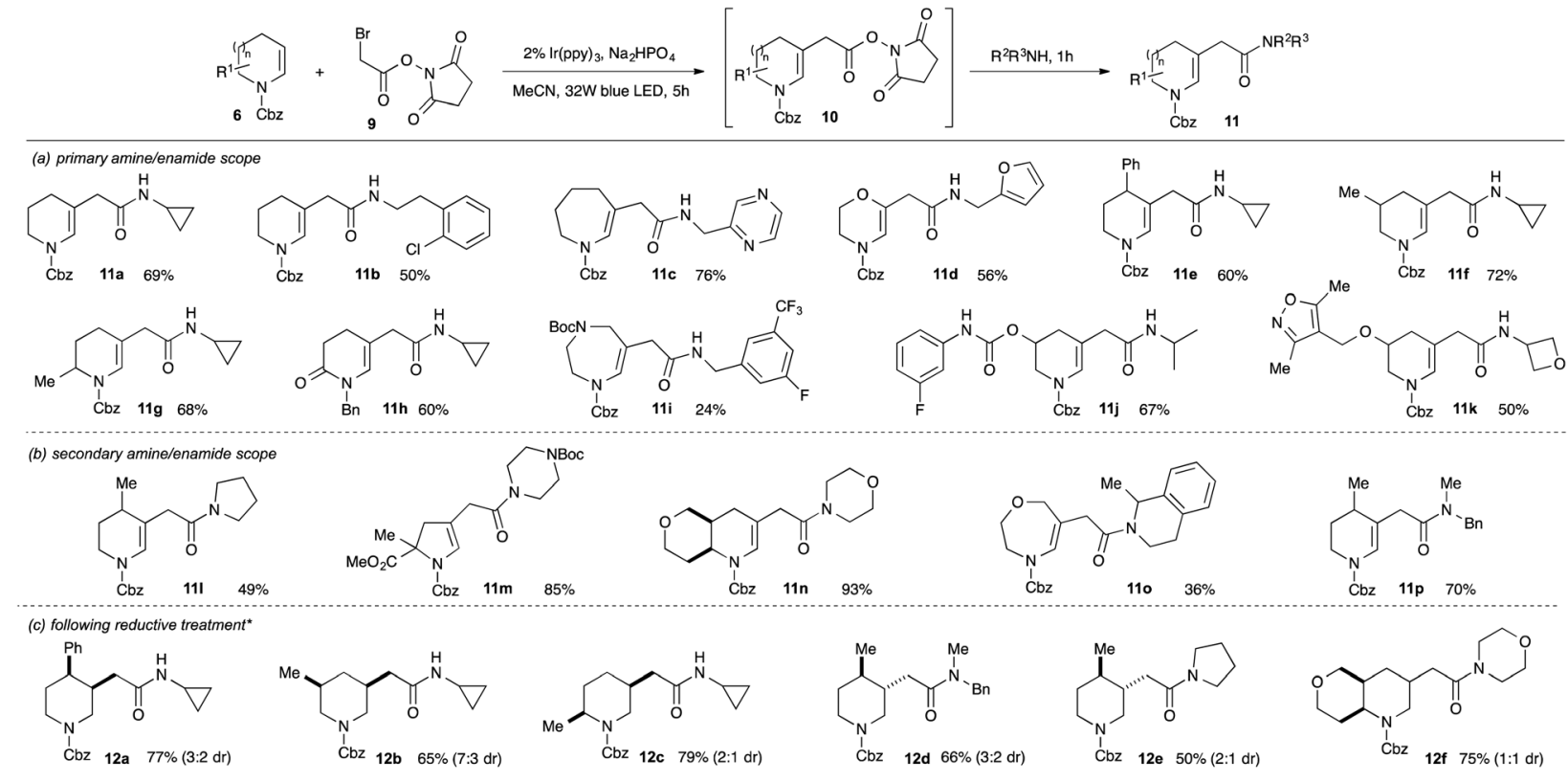

Scheme 3 Synthesis of acetamidomethyl-substituted enamides by coupling of enecarbamates with activated esters. * Panel c only: the crude reaction mixture was treated with triethylsilane and TFA in dichloromethane. 


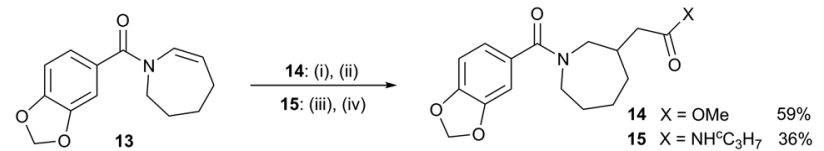

Scheme 4 Direct fragment growth and late-stage functionalisation of paroxetine using enecarbamate alkylation: (i) $2.2 \mathrm{~mol} \% \operatorname{Ir}(\mathrm{ppy})_{3}, 3$ equiv. $\mathrm{BrCH}_{2} \mathrm{CO}_{2} \mathrm{Me}, 2,6$-lutidine, $\mathrm{MeOH}, 32 \mathrm{~W}$ blue LED, 3 h; (ii) $\mathrm{Et}_{3} \mathrm{SiH}_{3} \mathrm{BF}_{3} \cdot \mathrm{OEt}_{2}$, $\mathrm{CH}_{2} \mathrm{Cl}_{2}$; (iii) $2.2 \mathrm{~mol} \% \operatorname{Ir}\left(\right.$ ppy) 3 , 3 equiv. 9, $\mathrm{Na}_{2} \mathrm{HPO}_{4}, \mathrm{MeCN}, 32 \mathrm{~W}$ blue LED, $5 \mathrm{~h}$, then ${ }^{\mathrm{C}} \mathrm{C}_{3} \mathrm{H}_{5} \mathrm{NH}_{2}, 1 \mathrm{~h}$; (iv) $\mathrm{Et}_{3} \mathrm{SiH}, \mathrm{TFA}, \mathrm{CH}_{2} \mathrm{Cl}_{2}$.

Finally we wished to demonstrate the application of the $\beta$-alkylation chemistry to the growth of a fragment hit. The piperonyl azepane 3 (Fig. 1) has been found via highthroughput X-ray crystallography to be a fragment hit for the m7GpppN-mRNA hydrolase DCP2B. ${ }^{22}$ The carbon atoms $\beta$-to the nitrogen have been identified as potential vectors for fragment growth, ${ }^{22}$ yet 3-carboxalkyl-substituted azepanes are not catalogue commodities, ${ }^{23}$ meaning de novo synthesis would be inevitable to exploit this vector. Instead, we were able to demonstrate introduction of a carboxymethyl group to enamide 13 by photoredox-mediated alkylation and reduction, giving ester 14 in 59\% yield (Scheme 4). Alternatively, amidoalkyl groups could be introduced using the protocol via the intermediate $N$-hydroxysuccinimidyl ester, giving e.g. amide 15 in $36 \%$ yield. We also used both approaches to effect late-stage functionalization of the anti-depressant paroxetine (ESI $\dagger$ ).

In summary, we have described methods for the challenging $\beta$-functionalisation of cyclic amines through regioselective conversion to enecarbamates and the subsequent installation of medicinally-relevant carboxyalkyl functionalities. We have further shown that the method can be used for regiospecific growth of fragment hits and in late-stage functionalization of complex products. The development of further methods for the direct elaboration of enecarbamates with medicinally-relevant functionality, as well as applications in fragment-based discovery projects, are ongoing.

We thank EPSRC (EP/N025652/1, EP/P016618/1) and EPSRC/ Astex (studentship to ELF) for funding. This project has received funding from the European Union's Horizon 2020 research and innovation programme under the Marie Skłodowska-Curie grant agreement no. MSCA-IF-2017-795189. Professor Frank von Delft (Diamond Light Source), and Drs Rachel Grainger and David Norton (Astex) are thanked for insightful comments. We acknowledge help from Research IT and use of the Computational Shared Facility (University of Manchester).

\section{Conflicts of interest}

There are no conflicts to declare.

\section{Notes and references}

1 D. A. Erlanson, S. W. Fesik, R. E. Hubbard, W. Jahnke and H. Jhoti, Nat. Rev. Drug. Discov., 2016, 15, 605-619.
2 A. L. Hopkins, G. M. Keseru, P. D. Leeson, D. C. Rees and C. H. Reynolds, Nat. Rev. Drug. Discov., 2014, 13, 105-121.

3 (a) J. Boström, D. G. Brown, R. J. Young and G. M. Keserü, Nat. Rev. Drug. Discov., 2018, 17, 709-727; (b) D. G. Brown and J. Boström, J. Med. Chem., 2016, 59, 4443-4458.

4 P. N. Mortenson, D. A. Erlanson, I. J. P. de Esch, W. Jahnke and C. N. Johnson, J. Med. Chem., 2019, 62, 3857-3872.

5 C. W. Murray and D. C. Rees, Angew. Chem., Int. Ed., 2016, 55, 488-492.

6 G. Chessari, I. M. Buck, J. E. Day, P. J. Day, A. Iqbal, C. N. Johnson, E. J. Lewis, V. Martins, D. Miller, M. Reader, D. C. Rees, S. J. Rich, E. Tamanini, M. Vitorino, G. A. Ward, P. A. Williams, G. Williams, N. E. Wilsher and A. J. Woolford, J. Med. Chem., 2015, 58, 6574-6588.

7 For representative reviews, see: (a) Y. Yang, J. Lan and J. You, Chem. Rev., 2017, 117, 8787-8863; (b) R. Rossi, F. Bellina, M. Lessi and C. Manzini, Adv. Synth. Catal., 2014, 356, 17-117; (c) D. Alberico, M. E. Scott and M. Lautens, Chem. Rev., 2007, 107, 174-238.

8 (a) R. D. Taylor, M. MacCoss and A. D. G. Lawson, J. Med. Chem., 2014, 57, 5845-5859; (b) E. Vitaku, D. T. Smith and J. T. Njardarson, J. Med. Chem., 2014, 57, 10257-10274.

9 For some recent examples, see: $(a)$ A. J. J. Lennox, S. L. Goes, M. P. Webster, H. F. Koolman, S. W. Djuric and S. S. Stahl, J. Am. Chem. Soc., 2018, 140, 11227-11231; (b) J. B. McManus, N. P. R. Onuska and D. A. Nicewicz, J. Am. Chem. Soc., 2018, 140, 9056-9060; (c) W. Chen, L. Ma, A. Paul and D. Seidel, Nat. Chem., 2018, 10, 165-169; (d) M. H. Shaw, V. M. Shurtleff, J. A. Terrett, J. D. Cuthbertson and D. W. C. MacMillan, Science, 2016, 352, 1304-1308; (e) D. T. Ahneman and A. G. Doyle, Chem. Sci., 2016, 7, 7002-7006.

10 R. Grainger, T. D. Heightman, S. V. Ley, F. Lima and C. N. Johnson, Chem. Sci., 2019, 10, 2264-2271.

11 See e.g.: (a) W. Chen, A. Paul, K. A. Abboud and D. Seidel, Nature Chem., 2020, 12, 545-550; (b) R. Oeschger, B. Su, I. Yu, C. Ehinger, E. Romero, S. He and J. F. Hartwig, Science, 2020, 368, 736-741; (c) J. Zhang, S. Park and S. Chang, J. Am. Chem. Soc., 2018, 140, 13209-13213; (d) A. Millet, P. Larini, E. Clot and O. Baudoin, Chem. Sci., 2013, 4, 2241-2247; (e) N. Takasu, K. Oisaki and M. Kanai, Org. Lett., 2013, 15, 1918-1921; $(f)$ B. Sundararaju, M. Achard, G. V. M. Sharma and C. Bruneau, J. Am. Chem. Soc., 2011, 133, 10340-10343.

12 (a) T. Shono, H. Hamaguchi and Y. Matsumara, J. Am. Chem. Soc., 1975, 97, 4264-4268; (b) T. Shono, Y. Matusmara, M. Ogaki and O. Onomura, Chem. Lett., 1987, 1447-1450.

13 S. Torii, T. Inokuchi, F. Akahosi and M. Kubota, Synthesis, 1987, 242-245.

14 T. Bach and H. Brummerhop, J. Prakt. Chem., 1999, 341, 312-315.

15 (a) A. M. Jones and C. E. Banks, Beilstein J. Org. Chem., 2014, 10, 3056-3072; (b) S. S. Libendi, Y. Demizu, Y. Matsumura and O. Onomura, Tetrahedron, 2008, 64, 3935-3942.

16 (a) T. Courant and G. Masson, Chem. - Eur. J., 2012, 18, 423-427; (b) O. K. Koleoso, M. R. J. Elsegood, S. J. Teat and M. C. Kimber, Org. Lett., 2018, 20, 1003-1006; (c) J.-H. Choi and C.-M. Park, Adv. Synth. Cat., 2018, 360, 3553-3562.

17 Isolated enamines: B. Hu, H. Chen, Y. Liu, W. Dong, K. Ren, X. Xie, H. Xu and Z. Zhang, Chem. Commun., 2014, 50, 13547-13550.

18 In situ generated enamines: (a) D. A. Nicewicz and D. W. C. MacMillan, Science, 2008, 322, 77-80; (b) Y. Zhu, L. Zhang and S. Luo, J. Am. Chem. Soc., 2014, 136, 14642-14645; (c) A. Gualandi, M. Marchini, L. Mengozzi, M. Natali, M. Lucarini, P. Ceroni and P. G. Cozzi, ACS Catal., 2015, 5, 5927-5931.

19 For isolated examples, see: $(a)$ primary enamides: J. Wu, M. Lang and J. Wang, Org. Lett., 2017, 19, 5653-5656; (b) enephosphamides: A. Franchino, A. Rinaldi and D. J. Dixon, $R S C$ Adv., 2017, 7, 43655-43659.

20 J. S. Carey, D. Laffan, C. Thomson and M. T. Williams, Org. Biomol. Chem., 2006, 4, 2337-2347.

21 T. Q. Chen and D. W. C. MacMillan, Angew. Chem., Int. Ed., 2019, 58, 14584-14588.

22 Accessible at fragalysis.diamond.ac.uk.

23 A search of commercially available compounds at reaxys.e-Molecules.com (18/11/2019) reveals a single compound (2-(1-Boc-azepane-3-yl)-acetic acid) available from a sole supplier by synthesis on demand. 